\title{
Morphology and identification of the final instar nymphs of three cicadas (Hemiptera, Cicadidae) in Guanzhong Plain, China based on comparative morphometrics
}

\author{
Zehai Hou', Qinglong Li', Cong Wei' \\ I Key Laboratory of Plant Protection Resources and Pest Management, Ministry of Education, Entomological \\ Museum, Northwest A\& F University, Yangling, Shaanxi 712100, China
}

Corresponding author: Cong Wei (congwei@nwsuaf.edu.cn)

Academic editor: Allen Sanborn | Received 14 May 2014 | Accepted 29 June 2014 | Published 10 July 2014

http://zoobank.org/4D992B73-A5F9-4BCC-9578-2125CD0EF873

Citation: Hou Z, Li Q, Wei C (2014) Morphology and identification of the final instar nymphs of three cicadas (Hemiptera, Cicadidae) in Guanzhong Plain, China based on comparative morphometrics. ZooKeys 425: 33-50. doi: $10.3897 /$ zookeys.425.7897

\begin{abstract}
The present investigation provides comparative morphometrics of the final instar nymphs of three dominant cicada species, i.e., Cryptotympana atrata (Fabricius), Meimuna mongolica (Distant) and Platypleura kaempferi (Fabricius), in Guanzhong Plain, China. Particularly, characters on the antennae, legs, and apex of abdomen of both males and females of these three species were investigated and analyzed. In addition, the numbers of hind tibial spines of the final instar nymphs of 21 representatives of Cicadoidea were compared. The results provide useful characteristics for nymph identification of related species and for further taxonomic and phylogenetic analysis of Cicadoidea.
\end{abstract}

\section{Keywords}

Cicadoidea, immature stage, underground pest

\section{Introduction}

Cicadas (Hemiptera, Cicadidae) are well known for their loud calling songs produced by male adults during summer (Young and Bennet-Clark 1995) and their long-term immature stage which is much longer than the adult stage, lasting several

Copyright Zehai Hou et al. This is an open access article distributed under the terms of the Creative Commons Attribution License (CC BY 4.0), which permits unrestricted use, distribution, and reproduction in any medium, provided the original author and source are credited. 
years underground (Boulard 1965, Pachas 1966, Logan 2006). During their subterranean lives from the first to final instars, cicada nymphs, burrowing through soil and feeding on xylem roots (White and Strehl 1978), may occasionally cause damage to their host plants. They have powerful forelegs modified for digging, and related morphological characters have been recognized for nymph identification in a few species by several authors (Boulard 1965, Pachas 1966, Hayashi 1976, Williams and Simon 1995, Ellingson et al. 2002). However, little information is available for nymph morphology or identification of most cicada species.

The cicadas Cryptotympana atrata (Fabricius), Meimuna mongolica (Distant) and Platypleura kaempferi (Fabricius), all belonging to the subfamily Cicadinae, are the three most dominant species in Guanzhong Plain of Shaanxi Province, China, which lies north of Qinling Mountains, the convergence zone of the Palaearctic and the Oriental regions and the natural boundary between northern and southern China. Like other cicadas, these three species, particularly Cr. atrata (a dominant pest in apple orchards of northen China), can cause great harm including twig dieback in host plants when large numbers of females insert eggs into the stems of trees and, furthermore, injuries caused by the feeding of them usually go undetected since their nymphs are long-lived underground (Zhu et al. 2012). Previous studies on these cicadas were mainly focused on adult morphology and taxonomy (Chou et al. 1997), and the morphology or morphometrics of the final instar exuviae (Kato 1931, Hayashi 1974, 1975, 1987; Lee et al. 2012). Herein, we investigate the morphometrics of the final instar nymphs of these three cicadas, aiming to give a detailed description of the final instar nymphs, compare the gross morphology among different species, and provide more information for nymph identification and future investigation about their biology, ontogeny and ethology.

\section{Materials and methods}

\section{Materials}

All nymphs of the final instar were collected by digging beneath the woods, i.e., Cr. atrata beneath Populus tomentosa Carr., P. kaempferi beneath Metasequoia glyptostroboides $\mathrm{Hu} \&$ Cheng, and M. mongolica beneath Pyrus xerophila Yü on the campus of Northwest A\&F University, Yangling, Shaanxi Province, China, from October to December, 2013. All captured nymphs were transferred alive to a beaker and anesthetized by chilling in a $4{ }^{\circ} \mathrm{C}$ refrigerator for morphological investigation. Exuviae and adult cicadas of the above three species were also collected on their host plants from June to July, 2013, respectively, aiming to confirm the identification of the final instar nymphs of each related species based on morphology. In addition, the nymphs of the final instar, exuviae and adult cicadas of Subpsaltria yangi Chen (belonging to the subfamily Tettigadinae) and Karenia caelatata Distant (belonging to the subfamily Cicadettinae) were also collected in the same way in Mts Helan, Ningxia Hui Autonomous Region, 
China, in June, 2012, and at Ningshan County in Mts Qinling, Shaanxi Province, China, in July and August, 2012, respectively. All the above mentioned materials and the exuviae of Cicadetta shansiensis (Esaki \& Ishihara) deposited in the Entomological Museum of Northwest A\&F University, China were examined, aiming to make a comparative morphological study on the hind tibial spines among these species and also other related species which have been investigated by some authors (Hayashi 1999; Maccagnan and Martinelli 2004, 2011; Logan and Connolly 2005).

\section{Methods}

Nymphs were classified to sex by the developing genitalia at the apex of abdomen. For males, the several terminal abdominal segments of part materials were slightly extracted to show the $9^{\text {th }}$ abdominal sternite if necessary, which was partly concealed by the $10^{\text {th }}$ abdominal sternite. Observations of the morphological features were carried out using a Motic SMZ168 Stereoscopic Zoom Microscope. Photographs were taken with a scientific digital micrography system equipped with an Auto-montage imaging system and a Qimaging Retiga 2000R digital camera (CCD). Drawings were made with the aid of a camera lucida attached to the microscope.

Twenty individuals (10 males and 10 females, respectively) of each species were measured. The measurements are as follows: (1) crown length (CL) measured on dorsal view along its median line from frontoclypeal suture to posterior margin of head (Fig. 1A); (2) pronotum length (PL) measured on dorsal view along its median line (Fig. 1A); (3) pro-mesonotum length (PML) measured on dorsal view from pronotum to mesonotum along its median line (Fig. 1A); (4) head width (HW) measured on dorsal view from the outside of one compound eye to the other (Fig. 1B); (5) pronotum width (PW) measured on dorsal view at the posterior margin (Fig. 1B); (6) body length (BL) measured on lateral view from the apex of postclypeus to the distal margin of abdomen (Fig. 1C); (7) wing length (WL) measured on lateral view from rim of pronotum to apex of wing pocket (Fig. 1C); (8) postclypeus length (PCL) measured on front view from its suture with the anteclypeus to the frontoclypeal suture (Fig. 1D); (9) postclypeus width (PCW) measured on front view from one side of the outermost edge of frontoclypeal to the other (Fig. 1D); (10) fore femur length (FL) measured along the median line of its external side (Fig. 1E); (11) fore tibiae length (TL) measured along the median line of its external side (Fig. 1E); (12) femoral tooth angle (FA) measured between the longitudinal axis of femur and its posterior tooth (Fig. 1E).

Among these measurements, FA was measured using the Image Lab version 2.2.4.0 software (MCM Design, Hillerød, Denmark). The remaining measurements were taken using a vernier caliper with the accuracy of $0.02 \mathrm{~mm}$.

Multivariate and univariate general linear model (GLM) analyses were conducted to determine whether morphological characters differed by species or sex. Statistical analyses were performed using SPSS 17.0. 

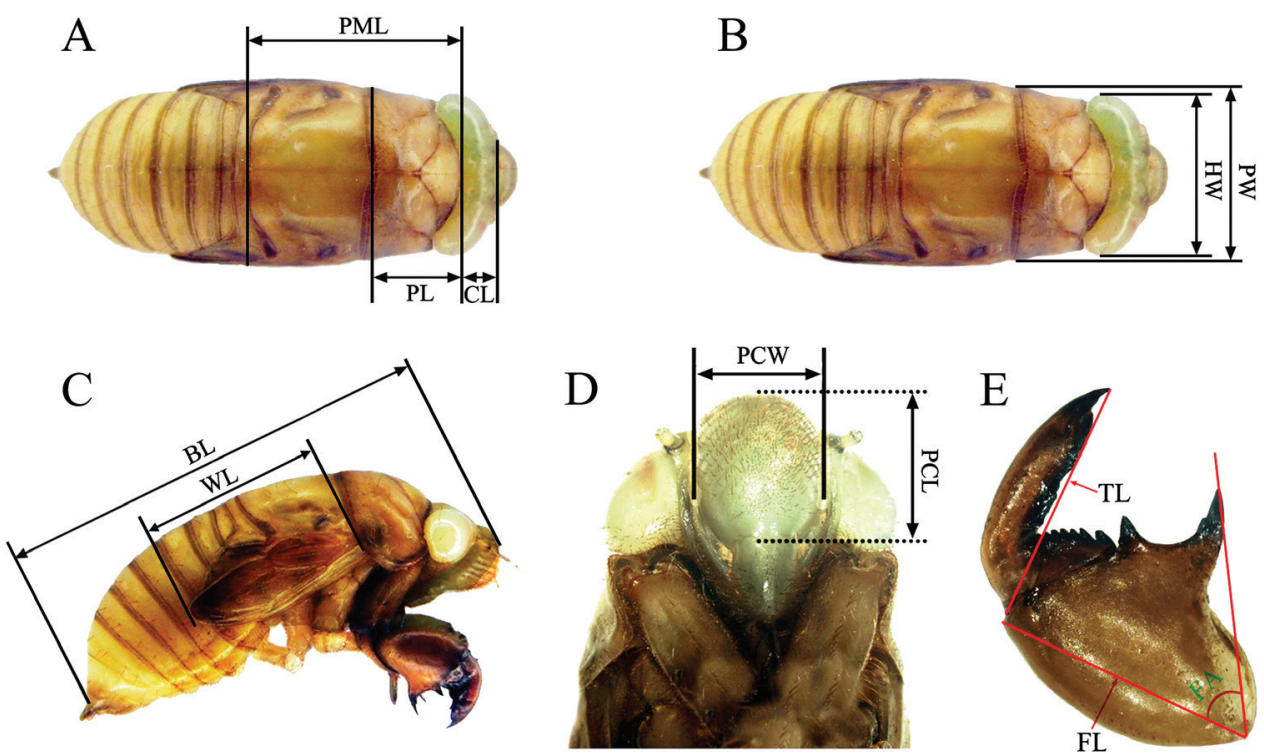

Figure I. Morphological characters of final instar nymphs used for measurements. BL body length; CL crown length; FA femoral tooth angle; FL fore femur length; HW head width; PCL postclypeus length; PCW postclypeus width; PML pro-mesonotum length; PL pronotum length; PW pronotum width; TL fore tibiae length; WL wing length.

The subfamily and tribal classification follows that of Moulds (2005). The terminology adopted to describe the structures of the foreleg was based on Duffels and Ewart (1988), and the femoral formula used to indicate the number and sequence of the teeth of fore femur was based on Maccagnan and Martinelli (2004).

\section{Results}

Morphology of the final instar nymph of Cryptotympana atrata (Fabricius, 1775)

\section{Cryptotympana atrata (Fabricius, 1775)}

Figs 2-5

Tettigonia atrata Fabricius, 1775: 681

Cicada atrata (Fabricius): Goeze 1778: 149

Tettigonia pustulata Fabricius, 1787: 266

Cicada nigra Olivier, 1790: 750

Fidicina bubo Walker, 1850: 82

Fidicina atrata (Fabricius): Walker 1850: 89

Cryptotympana atrata (Fabricius): Stål 1861: 613 
Cryptotympana sinensis Distant, 1887: 415

Cryptotympana dubia Haupt, 1917: 229

Cryptotympana coreanus Kato, 1925: 13

Cryptotympana santoshonis Matsumura, 1927: 49

Cryptotympana wenchewensis Ouchi, 1938: 82

Cryptotypmana pustulata castanea Liu, 1940: 82

Cryptotympana pustulata fukienensis Liu, 1940: 82

Measurements (mm or degree). Male $(\mathrm{n}=10)$ : BL $26.8(23.5-31.5)$, PCL $5.2(4.7-$ 5.5), PCW 5.2 (4.9-5.7), CL 3.1 (2.9-3.3), HW 11.7 (10.9-12.1), PL 8.3 (7.7-8.7), PW 14.3 (13.6-15.2), PML 16.5 (15.5-17.3), WL 12.6 (11.9-13.1), FL 6.2 (5.96.5), TL 6.6 (6.1-7.1), FA $71.4(69.5-73.2)$.

Female $(\mathrm{n}=10)$ : BL: 26.3 (23.3-29.7), PCL 5.2 (4.9-5.4), PCW 5.2 (5.0-5.3), CL 3.0 (2.8-3.2), HW 11.4 (10.5-12.1), PL 8.1 (7.3-8.7), PW 14.2 (13.6-15.1), PML 16.2 (15.2-17.0), WL 12.5 (11.5-13.1), FL 6.2 (5.7-6.5), TL 6.5 (6.0-7.0), FA $71.6(69.4-73.4)$.

Description. Body (Fig. 2A, B) dark brown, curved in lateral view, with sparse setae mainly on venter.

Head (Fig. 2B). Somewhat triangular in dorsal view; crown including white compound eyes about four times wider than long and about the same width as anterior margin of pronotum. Antenna brown, filiform. Postclypeus prominently swollen, covered with dense brown pile. Rostrum reaching to posterior coxae.

Thorax (Fig. 2A, B). Pronotum broad, paramedian and lateral fissures distinct, pronotal collar undeveloped, posterior margin distinctively concave medially in dorsal view. Mesonotum slightly wider than pronotum, with two small scutal depressions on disc. Metanotum very small. Fore wing bud developed, reaching to middle of $3^{\text {rd }}$ abdominal segment laterally; hind wing bud slightly developed.

Leg (Figs 5A, B, 6A, D). Generally dark brown. Fore femur with femoral formula 2-1-7: posterior tooth long and sharp, accessory tooth robust and sharp, intermediate tooth with projection in one of its sides; femoral comb usually with seven teeth, the first tooth about as large as the second tooth. Fore tibia arched, flattened laterally; apical tooth long; point of blade of tibia large and long, tooth-like, separated from apical tooth of blade by a strong incision. Apex of tibia with five spines in both mid and hind legs. Pretarsi of all legs well developed into a pair of claws of unequal sizes.

Abdomen (Fig. 4A-C). Size varying depends on the development of the nymph. In female, $8^{\text {th }}$ and $9^{\text {th }}$ sternites with two sharp posterior marginal protrusions. In male, $9^{\text {th }}$ sternite almost entirely concealed by $10^{\text {th }}$ sternite, four protrutions present on surface: a large triangular protrusion near lateral margins, respectively, and a pair of very small rounded protrusions on posterior margin; $10^{\text {th }}$ sternite smooth.

Variations of femoral comb. Ten percent $(2 / 20)$ of the individuals investigated with femoral comb with six teeth, instead of seven teeth. 

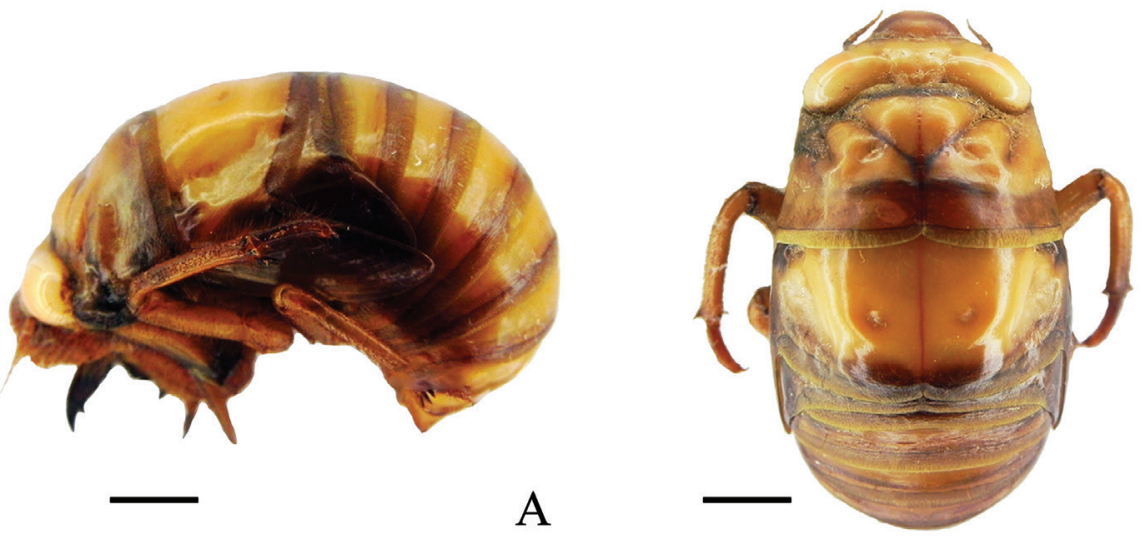

B
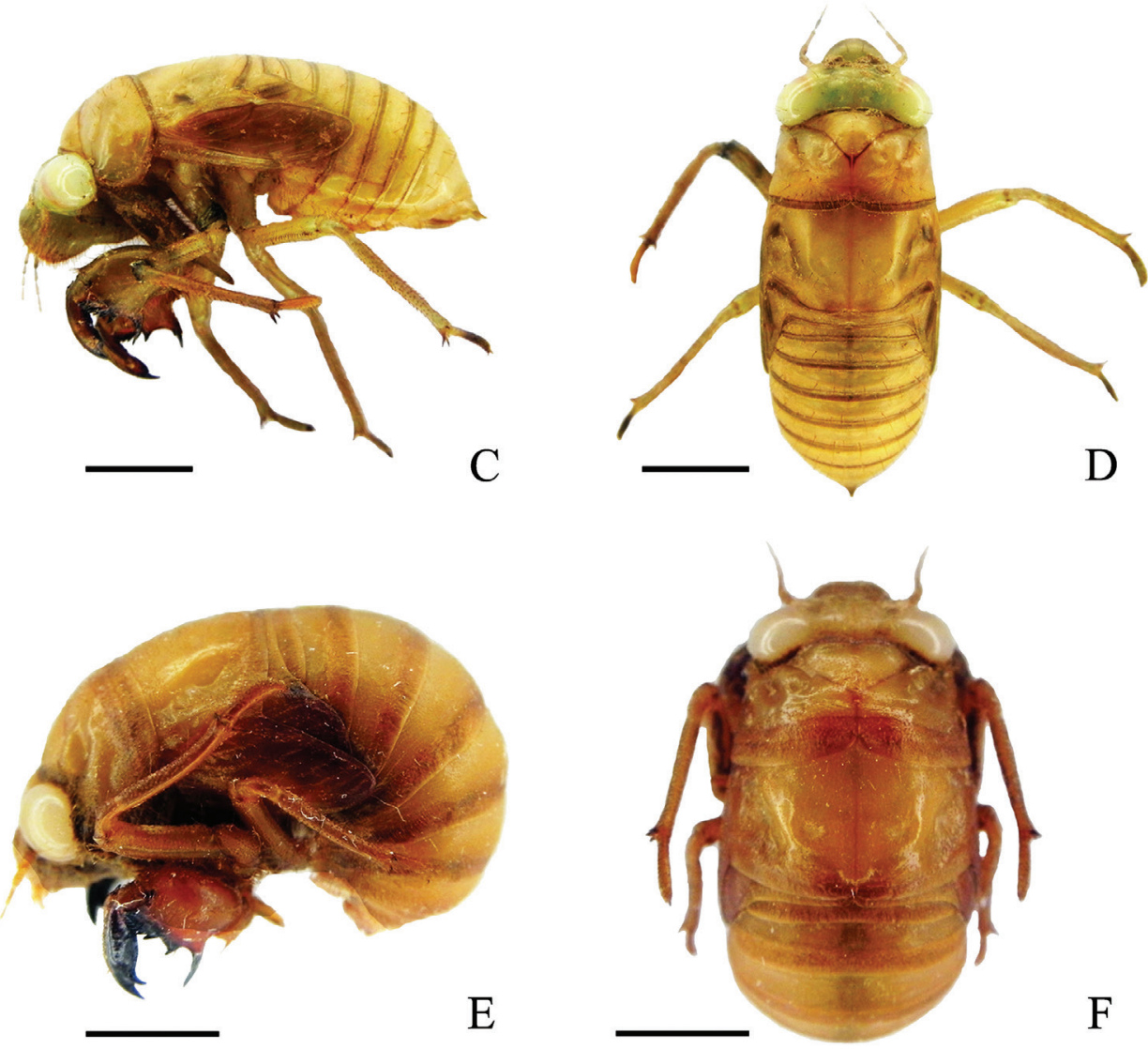

$\mathrm{F}$

Figure 2. Final instar nymphs. A Cryptotympana atrata, lateral view of body B $C$. atrata, dorsal view of body C Meimuna mongolica, lateral view of body D $M$. mongolica, dorsal view of body E Platypleura kaempferi, lateral view of body $\mathbf{F} P$. kaempferi, dorsal view of body. Scale bars $=5.0 \mathrm{~mm}$. 

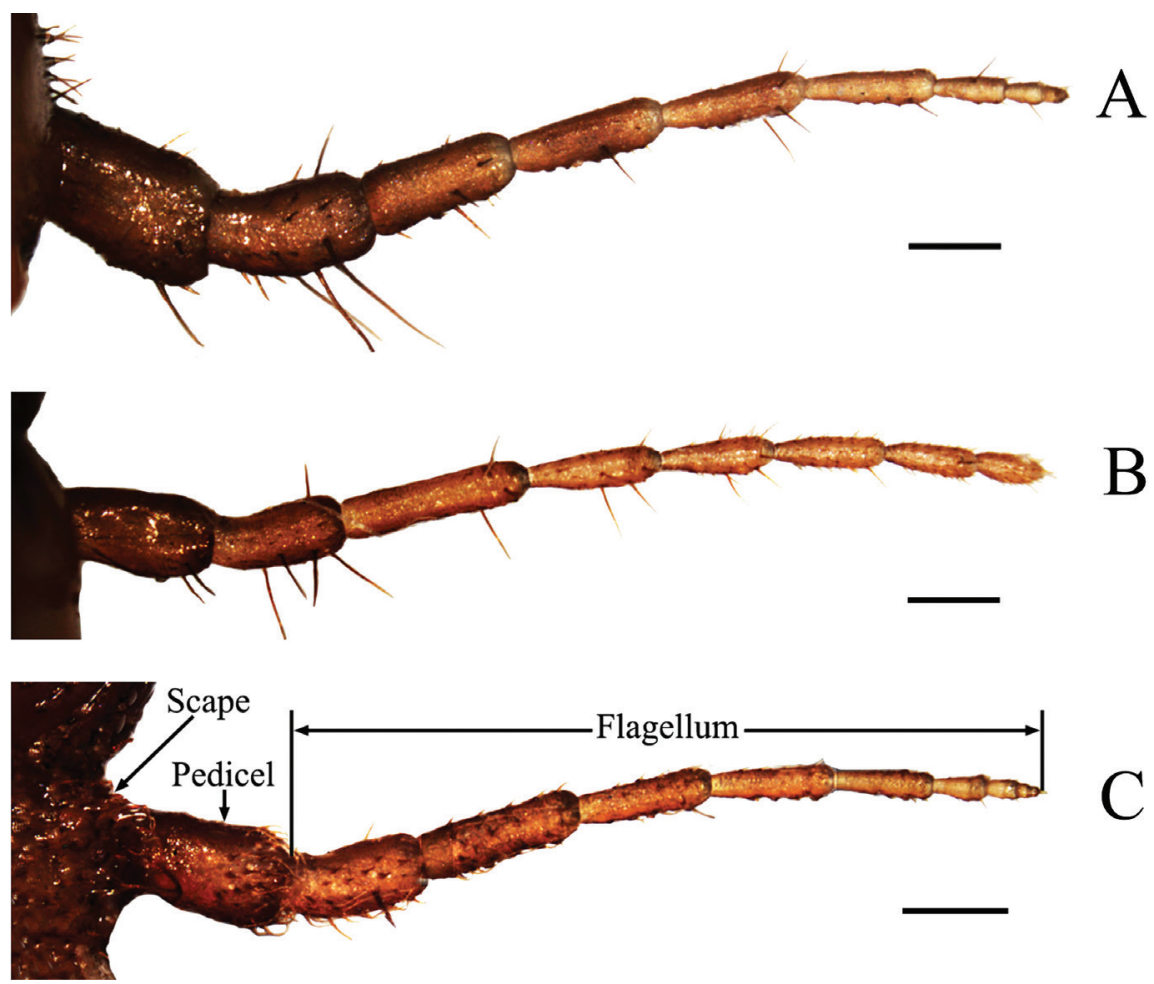

Figure 3. Antennae of final instar nymphs. A Cryptotympana atrata B Meimuna mongolica C Platypleura kaempferi. Scale bars $=0.5 \mathrm{~mm}$.

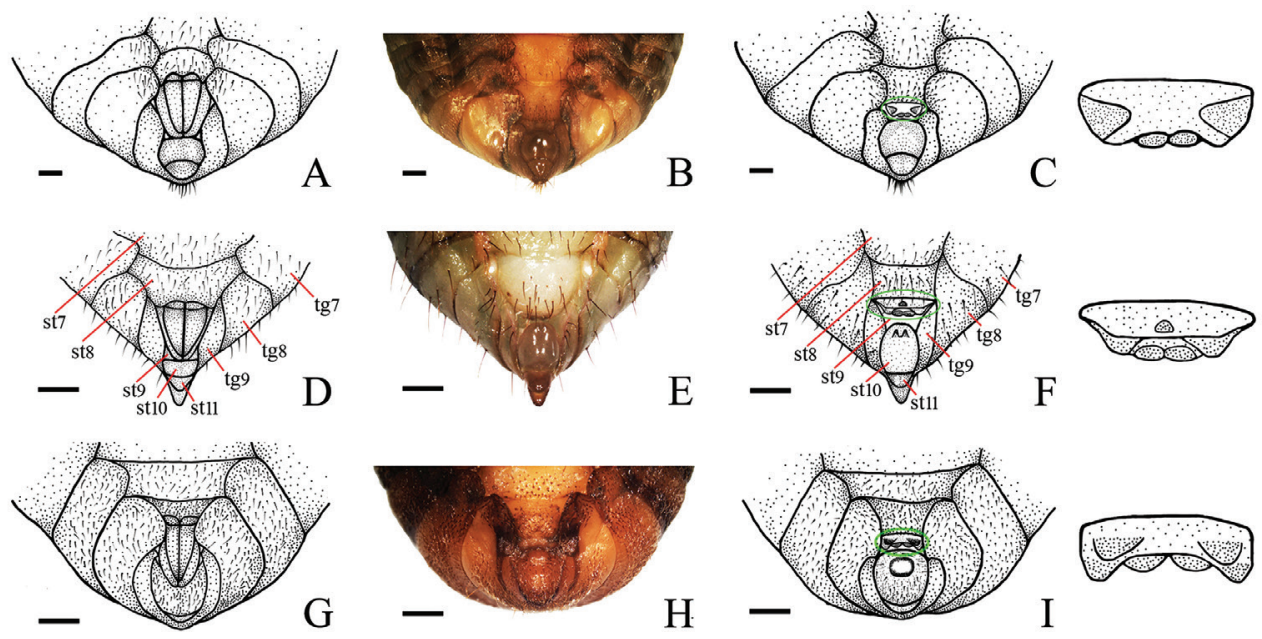

Figure 4. Abdominal apex in ventral view of final instar nymphs. A Cryptotympana atrata, female $\mathbf{B}$ and C $C$. atrata, male D Meimuna mongolica, female $\mathbf{E}$ and $\mathbf{F}$ M. mongolica, male $\mathbf{G}$ Platypleura kaempferi, female $\mathbf{H}$ and $\mathbf{I}$ P. Kaempferi, male. Scale bars $=1.0 \mathrm{~mm}$. 


\section{Morphology of the final instar nymph of Meimuna mongolica (Distant, 1881)}

\section{Meimuna mongolica (Distant, 1881)}

Figs 2-5

Cosmopsaltria mongolica Distant, 1881: 638

Meimuna mongolica (Distant): Distant 1906: 66

Meimuna suigensis Matsumura, 1927: 1

Meimuna chosensis Matsumura, 1927: 52

Meimuna heijonis Matsumura, 1927: 52

Meimuna santoshonis Matsumura, 1927: 52

Meimuna gallosi Matsumura, 1927: 52

Measurements (mm or degree). Male $(\mathrm{n}=10)$ : BL $19.8(18.0-21.3)$, PCL 3.5 (3.23.7), PCW 3.2 (2.9-3.5), CL 2.4 (2.2-2.7), HW 7.2 (6.8-7.7), PL 4.6 (4.4-4.8), PW 7.8 (7.3-8.2), PML 9.4 (8.7-9.8), WL 8.7 (8.0-9.4), FL 4.8 (4.5-5.0), TL 4.6 (4.3-4.8), FA 61.4 (60.5-62.8).

Female $(\mathrm{n}=10)$ : BL 19.1 (17.9-20.9), PCL 3.3 (3.1-3.6), PCW 3.0 (2.7-3.2), CL 2.2 (2.0-2.6), HW 6.9 (6.8-7.2), PL 4.4 (4.2-4.7), PW 7.5 (7.2-8.3), PML 8.9 (8.4-9.7), WL 8.4 (8.0-8.9), FL 4.7 (4.5-4.9), TL 4.5 (4.2-4.7), FA 61.4 (60.1-63.2).

Description. Body (Fig. 2C, D) pale brown, narrow and elongated, with setae scattered mainly on venter.

Head (Fig. 2D). Somewhat triangular in dorsal view; crown including white compound eyes about three times wider than long and slightly wider than anterior margin of pronotum. Antenna brown, filiform. Postclypeus prominently swollen, covered with dense brown pile. Rostrum reaching to posterior coxae.

Thorax (Fig. 2C, D). Pronotum broad, paramedian and lateral fissures distinct, pronotal collar undeveloped, posterior margin distinctively concave medially in dorsal view. Mesonotum slightly wider than pronotum, with two small scutal depressions on disc. Metanotum very small. Fore wing bud developed, reaching to middle of $4^{\text {th }}$ abdominal segment laterally, hind wing bud slightly developed.

Leg (Figs 5C, 6B, E). Generally dark brown. Fore femur with femoral formula 2-1-7 or 2-1-8: posterior tooth long and sharp, accessory tooth small, with apex somewhat blunt, intermediary tooth robust; femoral comb usually with seven or eight teeth, the first tooth about as large as the second tooth. Fore tibia arched, flattened laterally; apical tooth long; point of blade of tibia very small, toothlet-like, separated from apical tooth of blade by a very weak incision. Tibia with five apical spines in both mid and hind legs. Pretarsi of all legs well developed into a pair of claws of unequal sizes.

Abdomen (Fig. 4D-F). Size varying depending on the development of the nymph. In female, $8^{\text {th }}$ and $9^{\text {th }}$ sternites with two sharp posterior marginal protrusions. In male, $9^{\text {th }}$ sternite totally concealed by $10^{\text {th }}$ sternite, three protrusions present on surface: a smaller medial, coniform protrusion near anterior margin, and two larger rounded 
protrusions on posterior margin; $10^{\text {th }}$ sternite with two distinct projections adjacent to anterior margin.

Variations of femoral comb. Forty percent $(8 / 20)$ and $60 \%(12 / 20)$ of the individuals observed with seven and eight teeth on the femoral comb, respectively.

\section{Morphology of the final instar nymph of Platypleura kaempferi (Fabricius, 1794)}

\section{Platypleura kaempferi (Fabricius, 1794)}

Figs 2-5

Tettigonia kaempferi Fabricius, 1794: 23

Cicada kaempferi (Fabricius): Walker 1850: 117

Platypleura kaempferi (Fabricius): Butler 1874: 189

Platypleura fuscangulis Butler, 1874: 189

Platypleura hyalino-limbata Signoret, 1881: 62

Platypleura repanda Uhler, 1896: 276 (nec Linnaeus)

Platypleura tsuchidai Kato, 1936: 758

Platypleura retracta Liu, 1940: 74

Measurements (mm or degree). Male $(\mathrm{n}=10)$ : BL 19.0 (18.1-19.6), PCL 3.2 (3.13.5), PCW 3.3 (3.2-3.5), CL 2.2 (2.1-2.4), HW 7.5 (7.3-7.8), PL 4.7 (4.3-5.0), PW 9.2 (8.9-9.6), PML 10.0 (9.4-10.5), WL 7.4 (7.0-7.8), FL 4.1 (3.9-4.3), TL 4.5 (4.2-4.6), FA 77.1 (76.1-78.1).

Female $(\mathrm{n}=10)$ : BL 18.3 (17.7-18.6), PCL 3.1 (2.9-3.4), PCW $3.2(3.1-3.4)$, CL 2.1 (2.0-2.2), HW 7.3 (7.1-7.7), PL 4.6 (4.2-4.9), PW 8.9 (8.6-9.2), PML 9.8 (8.9-10.2), WL 7.2 (6.9-7.6), FL 4.0 (3.8-4.2), TL 4.3 (4.1-4.5), FA 77.2 (76.4-78.8).

Description. Body (Fig. 2E, F) brown, well curved in lateral view, with sparse setae mainly on venter.

Head (Fig. 2F). Somewhat triangular in dorsal view; crown including white compound eyes about three times wider than long and slightly wider than the anterior margin of the pronotum. Antenna brown, filiform. Postclypeus prominently swollen, covered with dense brown pile. Rostrum extending beyond posterior coxae.

Thorax (Fig. 2E, F). Pronotum broad, paramedian and lateral fissures distinct, pronotal collar developed, posterior margin distinctively concave medially in dorsal view. Mesonotum about as wide as pronotum, with two small scutal depressions on disc. Metanotum very small. Fore wing bud developed, reaching to middle of $3^{\text {rd }}$ abdominal segment laterally, hind wing bud slightly developed.

Leg (Figs 5D, 6C, F). Generally dark brown. Fore femur with femoral formula 2-1-7: posterior tooth long and sharp, accessory tooth robust and sharp, intermediate tooth with projection in one of its sides; femoral comb usually with seven teeth, the 

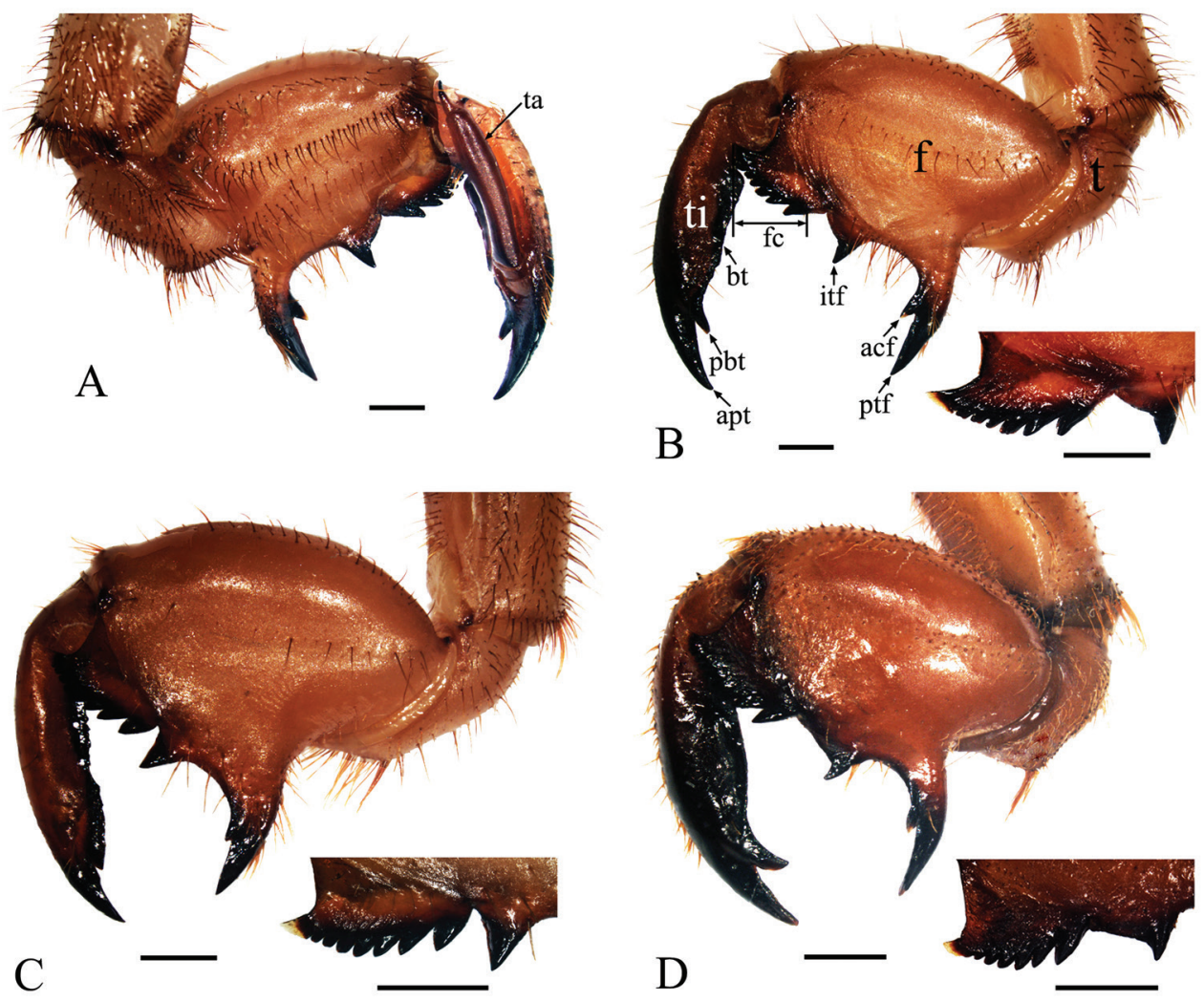

Figure 5. Left foreleg of final instar nymphs. A Cryptotympana atrata, inner view B C. atrata, outer view C Meimuna mongolica, outer view D Platypleura kaempferi, outer view. acf, accessory tooth of femur; apt, apical tooth of tibia; bt, blade of tibia; f, femur; fc, femoral comb; itf, intermediate tooth of femur; pbt, point of blade of tibia; ptf, posterior tooth of femur; t, trochanter; ta, tarsus; ti, tibia. Scale bars $=1.0 \mathrm{~mm}$

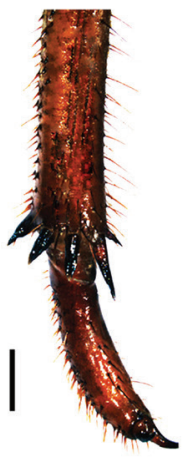

A

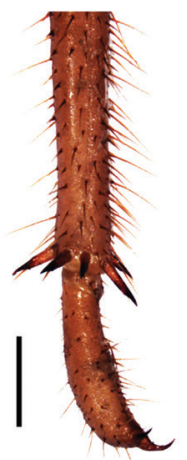

$\mathrm{B}$

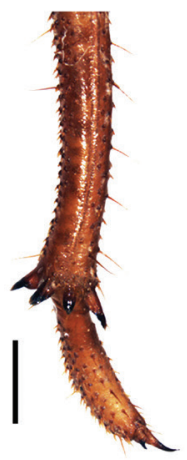

$\mathrm{C}$

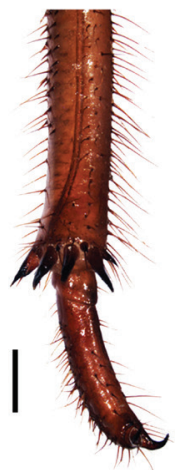

$\mathrm{D}$

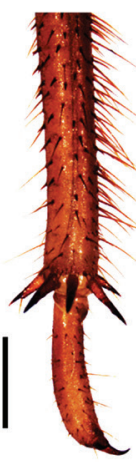

$\mathrm{E}$

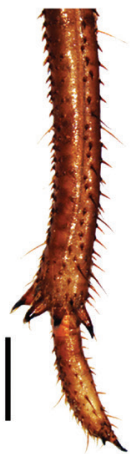

$\mathrm{F}$

Figure 6. Spines at the apex of mid and hind tibiae of final instar nymphs. A mid tibia of Cryptotympana atrata $\mathbf{B}$ mid tibia of Meimuna mongolica $\mathbf{C}$ mid tibia of Platypleura kaempferi $\mathbf{D}$ hind tibia of C. atrata $\mathbf{E}$ hind tibia of M. mongolica $\mathbf{F}$ hind tibia of P. Kaempferi. Scale bars $=1.0 \mathrm{~mm}$. 
first tooth distinctly larger than the second tooth. Fore tibia arched, flattened laterally; apical tooth long; point of blade of tibia large and long, tooth-like, separated from apical tooth of blade by a strong incision. Apex of tibia usually with four spines in both mid and hind legs, but sometimes with a very small accessory spine. Pretarsi of all legs well developed into a pair of claws of unequal sizes.

Abdomen (Fig. 4G-I). Size varying depending on the development of the nymph. In female, $8^{\text {th }}$ and $9^{\text {th }}$ sternites with two sharp posterior marginal protrusions. In male, $9^{\text {th }}$ sternite almost entirely concealed by $10^{\text {th }}$ sternite, six protrusions present on surface: two triangular protrusions adjacent to posterior margin, and four rounded protrusions on posterior margin; $10^{\text {th }}$ sternite with a very large, medial, globular protrusion adjacent to anterior margin.

Variations of femoral comb. Twenty percent (4/20) of the individuals studied with femoral comb with eight teeth, instead of seven teeth.

\section{Morphometrics and comparative morphology of antennae and forelegs among the three cicadas}

The results showed that the species (Wilks' $\lambda=0, \mathrm{~F}=817.078$, hypothesis $\mathrm{df}=24$, error $\mathrm{df}=90.000, \mathrm{P}=0$ ) was a significant factor for all morphological characters, and that sex (Wilks' $\lambda=0.469, \mathrm{~F}=4.241$, hypothesis $\mathrm{df}=12$, error $\mathrm{df}=45.000, \mathrm{P}=0$ ) was also significant for all characters, except for BL, FL and FA (Table 1).

There are great similarities in the gross morphology of antennae among the final instar nymphs of these three cicadas, i.e., the scape inserts in an antennal fovea of the cranium at the side of the postclypeus near an anterior tentorial pit, which is partially concealed in the antennal fovea and dorsally covered by the overhanging ridge of the vertex. However, differences also exist and are mainly shown in two aspects of these species: i) the shape of antennae (tapering apically in $\mathrm{Cr}$. atrata and P. kaempferi (Fig. 3A, C), but apical segment of flagellum in M. mongolica with full length in similar diameter (Fig. 3B)); and ii) the number of flagellar segments (seven in M. mongolica (Fig. 3B), eight in Cr. atrata (Fig. 3A) and nine in P. kaempferi (Fig. 3C)).

Similarly, though there are many similarities in the morphology of forelegs among the final instar nymphs of these three cicadas, differences also exist and are mainly shown in four aspects: $\mathrm{i}$ ) the shape of the base of posterior tooth on femur (extraordinarily broadened in M. mongolica (Fig. 5C), but moderately broadened in Cr. atrata and P. kaempferi (Fig. 5B, D)), ii) the shape of the base of intermediate tooth (extraordinarily broadened in Cr. atrata and P. kaempferi (Fig. 5B, D), but moderately broadened in $M$. mongolica (Fig. 5C)); iii) the shape of blade of tibia (with a large and long tooth-like point of blade of tibia in Cr. atrata and P. kaempferi (Fig. 5B, D), but with a very small, reduced apical toothlet-like point of blade of tibia in $M$. mongolica (Fig. 5C)); and iv) the femoral tooth angle (about $61^{\circ}, 71^{\circ}$ and $77^{\circ}$ in $\mathrm{M}$. mongolica, Cr. atrata and P. kaempferi, respectively). 
Table I. Results of univariate general linear model (GLM) for the morphological characters measured in cicada nymphs.

\begin{tabular}{|c|c|c|c|c|c|}
\hline Source & Variable & $\mathrm{df}$ & M.S. & $\mathrm{F}$ & $\mathrm{P}$ \\
\hline \multirow{12}{*}{ Species } & $\mathrm{BL}$ & 2 & 376.178 & 199.226 & 0.000 \\
\hline & PCL & 2 & 25.226 & 887.718 & 0.000 \\
\hline & PCW & 2 & 27.038 & 1002.519 & 0.000 \\
\hline & CL & 2 & 4.289 & 219.129 & 0.000 \\
\hline & HW & 2 & 121.916 & 1349.714 & 0.000 \\
\hline & $\mathrm{PL}$ & 2 & 87.079 & 1291.314 & 0.000 \\
\hline & PW & 2 & 245.548 & 1809.702 & 0.000 \\
\hline & PML & 2 & 314.792 & 1488.336 & 0.000 \\
\hline & WL & 2 & 150.091 & 963.221 & 0.000 \\
\hline & FL & 2 & 24.449 & 782.357 & 0.000 \\
\hline & $\mathrm{TL}$ & 2 & 27.888 & 631.693 & 0.000 \\
\hline & FA & 2 & 1271.572 & 1386.341 & 0.000 \\
\hline \multirow{12}{*}{ Sex } & $\mathrm{BL}$ & 1 & 6.144 & 3.254 & 0.077 \\
\hline & PCL & 1 & 0.131 & 4.598 & 0.036 \\
\hline & PCW & 1 & 0.171 & 6.328 & 0.015 \\
\hline & CL & 1 & 0.216 & 11.036 & 0.002 \\
\hline & HW & 1 & 0.963 & 10.658 & 0.002 \\
\hline & $\mathrm{PL}$ & 1 & 0.353 & 5.230 & 0.026 \\
\hline & PW & 1 & 0.561 & 4.132 & 0.047 \\
\hline & PML & 1 & 1.700 & 8.038 & 0.006 \\
\hline & WL & 1 & 0.662 & 4.245 & 0.044 \\
\hline & FL & 1 & 0.096 & 3.072 & 0.085 \\
\hline & $\mathrm{TL}$ & 1 & 0.241 & 5.451 & 0.023 \\
\hline & FA & 1 & 0.122 & 0.132 & 0.717 \\
\hline \multirow{12}{*}{ Error } & $\mathrm{BL}$ & 56 & 1.888 & & \\
\hline & PCL & 56 & 0.028 & & \\
\hline & PCW & 56 & 0.027 & & \\
\hline & $\mathrm{CL}$ & 56 & 0.020 & & \\
\hline & HW & 56 & 0.090 & & \\
\hline & PL & 56 & 0.067 & & \\
\hline & PW & 56 & 0.136 & & \\
\hline & PML & 56 & 0.212 & & \\
\hline & WL & 56 & 0.156 & & \\
\hline & FL & 56 & 0.031 & & \\
\hline & $\mathrm{TL}$ & 56 & 0.044 & & \\
\hline & FA & 56 & 0.917 & & \\
\hline
\end{tabular}

Comparison of the number of hind tibial spines and condition of intermediate tooth in 21 representatives of Cicadoidea

In Tettigarctidae, three hind tibial spines were found in Tettigarcta crinita Distant. In Cicadidae, the numbers of hind tibial spines of the final instar nymphs of different species are usually the same within a subfamily, but vary among different subfamilies (Table 2). In Tettigadinae, three hind tibial spines were observed in Subpsaltria yangi. 
In Cicadettinae, except for Cicadetta shansiensis with three and Karenia caelatata with five hind tibial spines, four hind tibial spines were observed in all other species: Amphipsalta cingulata (Fabricius), A. zelandica (Boisduval), Kikihia ochrina (Walker), Ki. scutellaris (Walker), Notopsalta sericea (Walker), Rhodopsalta cruentata (Fabricius), and Carineta fasciculata (Germar). In Cicadinae, three hind tibial spines were found in the genus Mogannia Amyot \& Audinet-Serville, four hind tibial spines in the genus Nipponosemia Kato, five hind tibial spines in the four investigated species ( $C r$. atrata (Fig. 6D), M. mongolica (Fig. 6E), Quesada gigas (Olivier) and Fidicina mannifera (Fabricius)), and four hind tibial spines with an additional small accessory spine internally were observed in the other four species, i.e., Dorisiana drewseni (Stål), D. viridis (Olivier), Fidicinoides pronoe (Walker) and P. kaempferi (Fig. 6F).

There are some differences in the situation of an intermediate tooth on fore femur from the femoral comb, e.g., continuous from the femoral comb, or well separated from the comb. For example, the intermediate tooth is continuous from the femoral comb in M. mongolica (Fig. 5C), Ci. shansiensis and Ka. caelatata; however, it is well separated from the comb in Cr. atrata (Fig. 5B), P. kaempferi (Fig. 5D) and S. yangi.

\section{Discussion}

The present study is the first to focus on the comparative morphology of the three cicadas in Guanzhong Plain. Cicadas usually have a long immature stage underground, which causes difficulties in their nymphal instar determination. A few species were reported to have five nymphal instars by some authors, e.g., Mogannia minuta Matsumura, Magicicada septendecim (Linnaeus), and Diceroprocta apache (Davis) (Hayashi 1976; Maier 1980; Ellingson et al. 2002); while a few other species were reported to have four instars by several authors, e.g., Cryptotympana atrata and Leptopsalta yamashitai (Esaki \& Ishihara) (Hu et al. 1990; Kang et al. 2005). The number of nymphal instars in cicadas needs to be readdressed based on more investigations. Though major similarities shared by nymphs of different instars within a species, the nymphs of final instar can be easily distinguished from the remaining instar nymphs by the well developed and rounded eye-capsule, the developed wing buds, and the apex of abdomen. In addition, some characteristics of the final instar nymphs are preserved in their exuviae, e.g., the femoral tooth angle, the shapes of foreleg and postclypeus, etc., which are informative for the recognition of the final instar nymphs from the remaining instar nymphs within a species. However, nymphs and adults of cicadas within a species have significant morphological differences which are closely related to their different ecological niches (Li and Wei 2013), and cause difficulties in species identification of most cicada nymphs. In the present study we show that the final instar nymphs of cicadas can be distinguished from each other according to their morphology. Among which, the differences of antennae and the $9^{\text {th }}$ and $10^{\text {th }}$ sternites in males may be important characters for taxonomic and phylogenetic analysis. In addition, the number of the hind tibial spines of the final instar nymphs may be an 


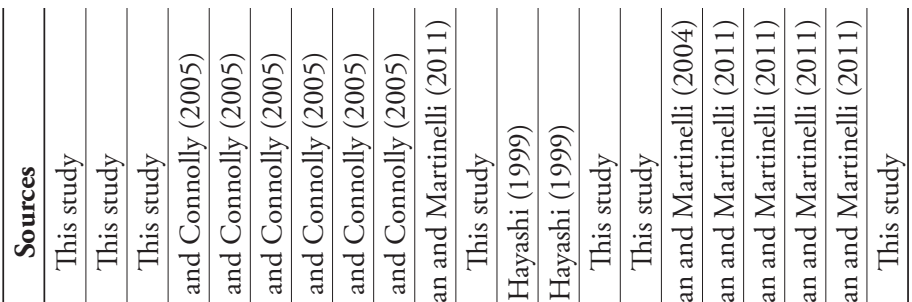

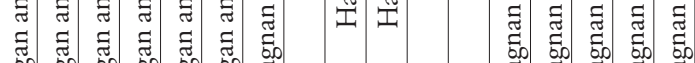

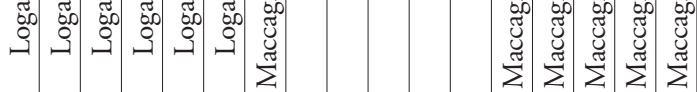

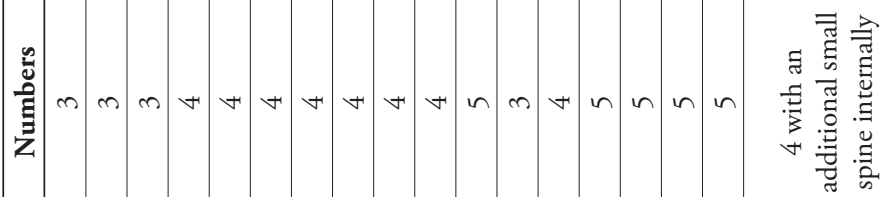

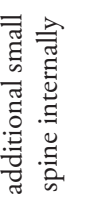

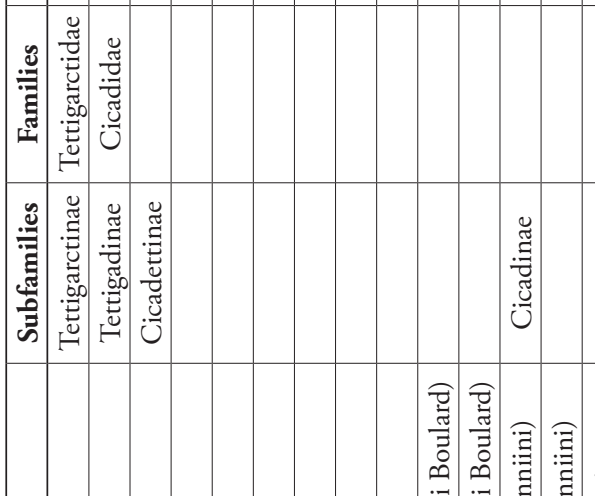

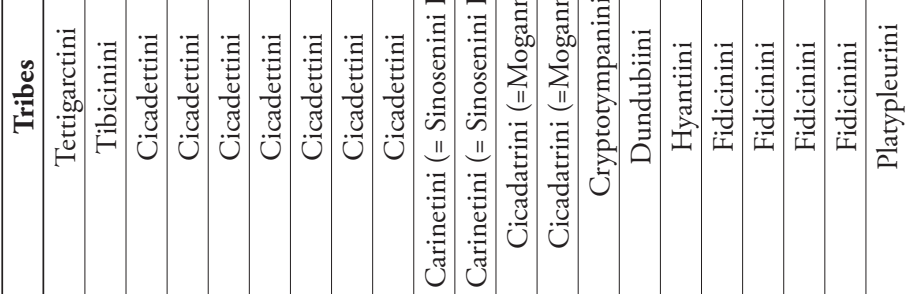

站

\%

(2)

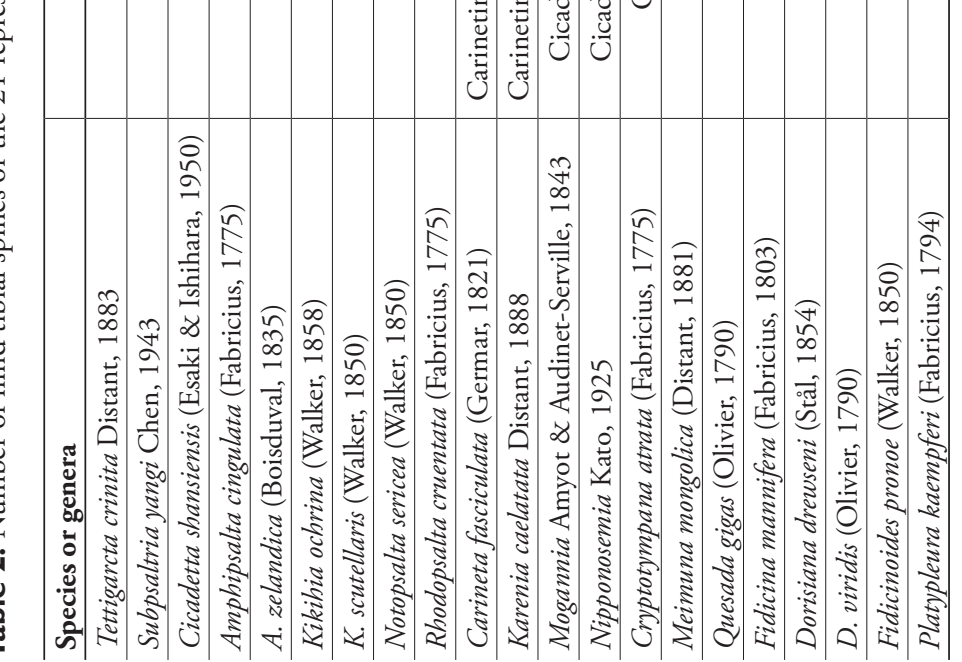


important morphological characteristic in phylogenetic analysis, although the number of hind tibial spines may be variable within a group, e.g., number of hind tibial spines of the genera Nipponosemia and Mogannia in the tribe Cicadatrini (=Moganniini) are 4 and 3, respectively (Hayashi 1999). The number of hind tibial spines of the final instar nymphs of more taxa need to be investigated when more materials become available. Surprisingly, the number of the hind tibial spines of the final instar nymphs of Karenia caelatata is 5, which is different with that of other investigated members of Cicadettinae, but is consistent with that of some members belonging to the Cicadinae, e.g., Cr. atrata, Meimuna mongolica, Fidicina mannifera, and Quesada gigas. Moulds (2005) and Boulard (2008) attributed the Karenia in the Cicadettinae (=Tibicininae auct.). However, the number of the hind tibial spines of the final instar nymphs together with some other characteristics of adults (e.g., metanotum distinctly concealed by the cruciform elevation on dorsal midline, uncus well developed with uncal lobes elongated apically, etc.) suggest that it seems more plausible to place this genus in the Cicadinae. The systematic placement of this genus needs further investigation.

Cicada nymphs could extend to $120 \mathrm{~cm}$ soil layer underground (Hugie and Passey 1963), though nymphs are most abundant within the well-rooted soil A horizon (eluvial horizon) and B horizon (illuvial horizon), typically between 10 and 30 $\mathrm{cm}$ from the ground surface (Luken and Kalisz 1989, O'Geen and Busacca 2001). However, burrowing depth of nymphal cicadas varies depending on the species. For example, our investigation showed that Platypleura kaempferi nymphs were located at $10-30 \mathrm{~cm}$ from the soil surface, being consistent with the results of Uematsu and Onogi (1980), and M. mongolica nymphs were mainly distributed in $21-30 \mathrm{~cm}$ soil layer and could extend to $60 \mathrm{~cm}$. Interestingly, significant differences were also observed in the forelegs of these two species. This suggests that the different burrowing depth in soil of the nymphs of different cicada species should be closely related to the development of their forelegs, and that the forelegs may provide promising characters for taxonomy and for future investigation about biology, ontogeny and ethology of related species.

\section{Acknowledgments}

The authors thank Prof. Chris Simon (University of Connecticut, Storrs, USA) for providing her manuscript on the cicada life cycle phenology focusing on early stages and for her discussion with us, which provided valuable information for this study. The authors are grateful to Prof. Masami Hayashi (Saitama University, Japan) for critical reviewing the manuscript and offering valuable comments when he was visiting the Entomological Museum, Northwest A\&F University, China in June, 2014. This work was supported by the National Natural Science Foundation of China (Grant No. 31170360, 31093430) and Program for New Century Excellent Talents in Universities of China (NCET-10-0691) to CW. 


\section{References}

Boulard M (1965) Notes sur la biologie larvaire de las cigales (Hom. Cicadidae). Annales de la Société Entomologique de France 1(3): 503-521.

Boulard M (2008) Les cigales thaïes. Liste actualisée (Biodiversité, Biogéographie et Bibliographie) incluant les diagnoses de deux nouneaux genres, les descriptions de sept espèces nouvelles et les Cartes d'identité Acoustique (CIA) de Chremistica siamensis Bregman et de Leptopsaltria samia (Walker), (Rhynchota, Cicadomorpha, Cicadidae). EPHE, Biologie et Evolution des Insectes 18: 1-112.

Chou I, Lei ZR, Li L, Lu XL, Yao W (1997) The Cicadidae of China (Homoptera: Cicadoidea). Tianze Eldoneio, Hong Kong, 380 pp. [in Chinese with English summary]

Distant WL (1881) Descriptions of new species belonging to the homopterous family Cicadidae. Transactions of the Royal Entomological Society of London 29(4): 627-648. doi: 10.1111/j.1365-2311.1881.tb00885.x

Distant WL (1887) Descriptions of two new species of Cicadidae. Annals and Magazine of Natural History (5) 20: 226-231.

Distant WL (1906) A synonymic catalogue of Homoptera. Part 1. Cicadidae. Trustees of the British Museum, London, 207 pp.

Duffels JP, Ewart A (1988) The cicadas of the Fiji, Samoa and Tonga Island, their taxonomy and biogeography (Homoptera: Cicadoidea). Leiden, Scandinavian Science Press, 108 pp. [Entomograph, 10]

Ellingson AR, Andersen DC, Kondratieff BC (2002) Observations of the larval stages of Diceroprocta apache Davis (Homoptera: Tibicinidae). Journal of the Kansas Entomological Society 75(4): 283-289.

Fabricius JC (1775) Systema Entomologiae, sistens insectorum classes, ordines, genera, species, adiectis synonymis, locis, descriptionibus, observationibus. Korte, Flensburg \& Leipzig, 832 pp. doi: 10.5962/bhl.title.36510

Fabricius JC (1787) Rhyngota. Mantissa insectorum sistens species nuper detectas adiectis synonymis, observationibus, descriptionibus, emendationibus, 2: $382 \mathrm{pp}$.

Haupt H (1917) Neue paläarktische Homoptera nebst Bemerkungen über einige schon bekannte. Wiener Entomologische Zeitung 36: 229-262.

Hayashi M (1974) The cicadas of the genus Platypleura (Homoptera, Cicadidae) in the Ryukyu Archipelago, with the description of a new species. Kontyû 42(3): 232-253.

Hayashi M (1975) On the species of the genus Meimuna Distant (Homoptera, Cicadidae) of the Ryukyus I. Synonymy and description of the species. Kontyû 43(3): 281-298.

Hayashi M (1976) Description of the nymphs of Mogannia minuta Matsumura (Homoptera, Cicadidae), pest of sugarcane in the Ryukyus. Kontyû 44(2): 142-149.

Hayashi M (1987) A revision of the genus Cryptotympana (Homoptera, Cicadidae) Part II. Bulletin of the Kitakyushu Museum of Natural History 7: 1-109.

Hayashi M (1999) Cicadidae. In: Aoki J (Ed) Pictorial keys to soil animals of Japan. Tokai University Press, Tokyo, 832-848. [in Japanese]

Hu ZL, Han CX, Shi DX, Dong ZT, Liu YM (1990) A preliminary observation on the biological habit of Cryptotympana atrata. Shaanxi Forest Science and Technology 3: 43-48. [in Chinese] 
Hugie VK, Passey HB (1963) Cicadas and their effect upon soil genesis in certain soils in southern Idaho, northern Utah, and northeastern Nevada. Soil Science Society of America Journal 27(1): 78-82. doi: 10.2136/sssaj1963.03615995002700010027x

Kang KG, Sun BY, Kang JX, Qiang L, Lei Q (2005) Preliminary analysis of nymph ages division of Leptopsalta yamashitai (Esaki and Ishihara), comb. nov. Journal of Northwest Forestry University 20(4): 122-123. [in Chinese]

Kato M (1925) Japanese Cicadidae, with descriptions of new species. Transactions of the Natural History Society of Formosa 15: 1-47. [in Japanese]

Kato M (1931) A classification of the exuviae of Cicadidae. Zoological Magazine 43: 497-503. [in Japanese]

Kato M (1936) Notes on Cicadidae, 9. Entomological World, volume 4, Tokyo, 758-765.

Lee HY, Oh SY, Jang Y (2012) Morphometrics of the final instar exuviae of five cicada species occurring in urban areas of central Korea. Journal of Asia-Pacific Entomology 15(4): 627-630. doi: 10.1016/j.aspen.2012.07.004

Li QL, Wei C (2013) Antennal morphology of the cicada Meimuna mongolica (Distant) (Hemiptera: Cicadidae), with a deduction of its nymphal instars and discussion of the antennal morphological variations in relation to niche changes. Entomotaxonomia 35: 81-94.

Liu GK-C (1940) New Oriental Cicadidae in the Museum of Comparative Zoology. Harvard University and Museum of Comparative Zoology Bulletin 87: 73-117.

Logan D, Connolly P (2005) Cicadas from kiwifruit orchards in New Zealand and identification of their final instar exuviae (Cicadidae: Homoptera). New Zealand Entomologist 28(1): 37-48. doi: 10.1080/00779962.2005.9722684

Logan D (2006) Nymphal development and lifecycle length of Kikihia ochrina (Walker) (Homoptera: Cicadidae). The Weta 31: 19-22.

Luken JO, Kalisz PJ (1989) Soil disturbance by the emergence of periodical cicadas. Soil Science Society of America Journal 53(1): 310-313. doi: 10.2136/ sssaj1989.03615995005300010060x

Maccagnan DHB, Martinelli NM (2004) Descrição das ninfas de Quesada gigas (Olivier) (Hemiptera: Cicadidae) associadas ao cafeeiro. Neotropical Entomology 33(4): 439-446. doi: 10.1590/S1519-566X2004000400007

Maccagnan DHB, Martinelli NM (2011) Description and key to the fifth-instars of some Cicadas (Hemiptera: Cicadidae) associated with coffee plants in Brazil. Neotropical Entomology 40(4): 445-451. doi: 10.1590/S1519-566X2011000400006

Maier CT (1980) A mole's-eye view of seventeen-year periodical cicada nymphs, Magicicada septendecim (Hemiptera: Homoptera: Cicadidae). Annals of the Entomological Society of America 73(2): 147-152.

Matsumura S (1927) New species of Cicadidae from the Japanese Empire. Insecta Matsumurana 2(1): 46-58.

Moulds MS (2005) An appraisal of the higher classification of cicadas (Hemiptera: Cicadoidea) with special reference to the Australian fauna. Records of the Australian Museum 57: 375-446. doi: 10.3853/j.0067-1975.57.2005.1447

O'Geen AT, Busacca AJ (2001) Faunal burrows as indicators of paleo-vegetation in eastern Washington, USA. Palaeogeography, Palaeoclimatology, Palaeoecology 169: 23-37. doi: 10.1016/S0031-0182(01)00213-9 
Olivier GA (1790) Cigale, Cicada. Encyclopédie Méthodique Histoire Naturalle Insectes 5: 735-760.

Ouchi Y (1938) A preliminary note on some Chinese cicadas with two new genera. Journal of the Shanghai Science Institute (3) 4: 75-111.

Pachas PO (1966) La chicharra de la yerba mate (Fidicina mannifera, Fab., 1803) su biologíae observaciones sobre los métodos de control en Misiones (República Argentina). Idia 217: 5-15.

Stål C (1861) Genera nonnulla nova cicadinorum. Annales de la Société Entomologique de France (4) 1: 613-622.

Uematsu S, Onogi S (1980) The distribution of Platypleura kaempferi (Fabricius) (Homoptera: Cicadidae) nymphs in the soil of a loquat fruit tree orchard. Japanese Journal of Applied Entomology and Zoology 24(2): 108-110. doi: 10.1303/jjaez.24.108

Walker F (1850) List of the specimens of homopterous insects in the collection of the British Museum. Part 1. British Museum, London, 260 pp.

White J, Strehl CE (1978) Xylem feeding by periodical cicada nymphs on tree roots. Ecological Entomology 3(4): 323-327. doi: 10.1111/j.1365-2311.1978.tb00933.x

Williams KS, Simon C (1995) The ecology, behavior, and evolution of periodical cicadas. Annual Review of Entomology 40(1): 269-295. doi: 10.1146/annurev.en.40.010195.001413

Young D, Bennet-Clark HC (1995) The role of the tymbal in cicada sound production. Journal of Experimental Biology 198(4): 1001-1019.

Zhu HH, He H, Wei C (2012) Oviposition and control of Cryptotympana atrata (Fabricius) in apple orchards of Weibei Region, Shaanxi, China. Forest Pest and Disease 31(6): 8-12. 